* Pejorative expressions that mean mentally ill black man and woman, respectively

** The word

aquilombamento derives from the term quilombo, a settlement of fugitive black slaves in Brazil. A number of those settlements continued to exist after the emancipation of slaves in 1888 and remain today as places that preserve unique features of African-Brazilian culture. Thus, aquilombamento is a new concept that means making something similar to a quilombo, so as to stress the empowerment of African-Brazilians and their culture.
1 Pontifícia Universidade

Católica de São Paulo (PUC-SP), Núcleo de Pesquisa em Lógicas Institucionais e Coletivas São Paulo (SP), Brasil. emilianocamargodavid@ yahoo.com.br

\section{Nem crioulo doido nem negra maluca: por um aquilombamento da Reforma Psiquiátrica Brasileira}

\author{
Neither crioulo doido* nor negra maluca*: for an aquilombamento** \\ of the Brazilian Psychiatric Reform
}

Emiliano de Camargo David', Maria Cristina Gonçalves Vicentin $\mathbf{1}$

DOI: $10.1590 / 0103-11042020$ E322

RESUMO Considerando que o manicômio enquanto instituição reproduz uma lógica de dominação racista que serviu (e ainda serve) para o encarceramento da população negra brasileira ao longo dos anos, este artigo discute a relação entre racismo e manicomialização. Para tanto, por meio de revisão de literatura, apresentam-se duas dimensões em que essa relação mais agudamente se expressa - o racismo científico brasileiro e a ideologia do branqueamento -, assim como o atrelamento entre raça negra e loucura no Brasil em três diferentes tempos de experiências asilares: século XIX, no Hospital Nacional de Alienados, com as experiências de Dr. Henrique Roxo; nas primeiras décadas do século XX, com Dr. Pacheco e Silva e a Liga Paulista de Higiene Mental no Hospital do Juquery; e no início do século XXI, nos anos 2000, com o Censo Psicossocial dos Moradores em Hospitais Psiquiátricos do Estado de São Paulo. Em diálogo com uma leitura decolonial da proposta da Reforma Psiquiátrica Brasileira, aponta-se a urgente e necessária implementação de práticas antirracistas na Rede de Atenção Psicossocial enquanto tarefa antimanicomial contemporânea, o que se chama de aquilombamento.

PALAVRAS-CHAVE Racismo. Hospitais psiquiátricos. Saúde mental.

\begin{abstract}
Considering mental institutions as reproductive of a logic of racist domination and that such logic was (and still is) used to justify the incarceration of the Brazilian black population, this article discusses the relation between racism and institutionalization. To that end, through a review of literature, we present two dimensions in which this relation is acutely expressed: Brazilian scientific racism, the ideology of whitening and the idea that the black race and madness are connected in three periods of mental asylum experiences: in the 19th century, in the National Hospital for the Mentally Ill, with Dr. Henrique Roxo's experiments; in the first decades of the 20th century, with Dr. Pacheco e Silva and the São Paulo State Mental Health League in the Juquery Hospital; and in the 2000s, with the São Paulo State Psychosocial Census of Mental Hospital Residents. In dialog with a decolonial reading of the Brazilian psychiatric reform, we point to an urgent and necessary implementation of anti-racist practices in the Psychosocial Care Network as a contemporary anti-institutional task, which we call aquilombamento**.
\end{abstract}

KEYWORDS Racism. Psychiatric Hospitals. Mental Health. 


\section{Introdução}

A Reforma Psiquiátrica Brasileira, em dois dos seus principais manifestos, a 'Carta de Bauru'1 e a 'Carta de Bauru - 30 anos' 2 , sustenta que o racismo é uma configuração manicomial. Em 1987, usuários(as), trabalhadores(as), militantes, pesquisadores(as), estudantes, familiares, entre outros(as), já apontavam o combate à discriminação contra negros(as) como uma pauta antimanicomial:

O manicômio é expressão de uma estrutura, presente nos diversos mecanismos de opressão desse tipo de sociedade. A opressão nas fábricas, nas instituições de adolescentes, nos cárceres, a discriminação contra negros, homossexuais, índios, mulheres. Lutar pelos direitos de cidadania dos doentes mentais significa incorporar-se à luta de todos os trabalhadores por seus direitos mínimos à saúde, justiça e melhores condições de vida?.

Em 2017, representantes das mesmas esferas se manifestaram defendendo a igualdade racial, posicionando-se contra o genocídio e a criminalização de jovens negros(as) e reconhecendo a urgência de articulação com o movimento social negro:

Não podemos deixar de frisar o avanço do conservadorismo e da criminalização dos movimentos sociais, defendemos a diversidade sexual e de gênero, as pautas feministas, a igualdade racial. Somos radicalmente contra o genocídio e a criminalização da juventude negra, a redução da maioridade penal, a intolerância religiosa e todas as formas de manicômio, que seguem oprimindo e aprisionando sujeitos e subjetividades. Apontamos a necessidade urgente de articulação da Luta Antimanicomial com os movimentos feministas, negro, LGBTTQI, movimento da população de rua, por trabalho, moradia, indígena entre outros, a fim de construirmos lutas conjuntas²(2).

Ambos os documentos pautam a dimensão racial, apontando uma direção ético-política que não separa as lutas antirracistas da luta antimanicomial. De fato, se entendemos que a lógica manicomial, ou a manicomialização, não se esgota no manicômio como estabelecimento asilar, mas está presente na sociedade, as relações entre luta antimanicomial e decolonialidade ficam mais evidentes. Como apontam Amarante ${ }^{3}$ e Yasui ${ }^{4}$, a Reforma Psiquiátrica no Brasil é um processo social complexo que coloca em jogo dimensões jurídico-políticas, epistemológicas, socioculturais, além das técnico-assistenciais.

Entendemos tal direção da Reforma como uma perspectiva decolonial. Se, na lógica manicomial, o manicômio se reproduz e permanece para além do asilo, na perspectiva decolonial, a colonialidade está além do colonialismo. Entendemos colonialidade, tal como formulada por Quijano 5 , como a "imposição de uma classificação racial/étnica da população do mundo"5(84), como

pedra angular de um padrão de poder que opera nas dimensões materiais e subjetivas da existência social cotidiana e da escala social, que se origina e se mundializa a partir da América5(84).

Nesse sentido, como lógica de poder, ela ultrapassa a experiência inaugural do 'colonialismo', enquanto processo sociopolítico-econômico de colonização e escravidão (infligido, do século XV ao XIX, nas Américas).

No entanto, mesmo na dimensão técnico-assistencial, a análise dos efeitos das discriminações raciais e do racismo assim como a assunção de condutas antirracistas pela Rede de Atenção Psicossocial6 (Raps) - que articula os pontos de atenção à saúde para pessoas com sofrimento ou transtorno mental e com necessidades decorrentes do uso de álcool e outras drogas - seguem invisibilizadas ou inexistentes, fazendo com que políticas fundamentais para o cuidado em saúde/ saúde mental da população negra não sejam incorporadas no dia a dia dos equipamentos do Sistema Único de Saúde (SUS), como é o caso da Política Nacional de Saúde Integral da População Negra (PNSIPN). 
É importante frisar que a Política Nacional de Saúde Mental no Brasil, instituída em 20017, e a PNSIPN, instituída em $2010^{8}$, aproximam-se, e ambas buscam equidade, além da universalidade, avalizando que o cuidado em saúde se dá no dever de atender igualmente o direito de cada um, porém, reconhecendo suas especificidades e valorizando diferenças.

Este artigo baseia-se em dissertação de mestrado em Psicologia Social ${ }^{9}$ que buscou discutir as relações entre racismo e saúde mental na perspectiva dos profissionais de um Centro de Atenção Psicossocial Infantojuvenil (Capsi), tendo como um dos eixos de revisão de literatura os processos de asilamento da população negra no País. Inicialmente, apresentamos a relação histórica entre loucura e raça no Brasil, com foco nos mecanismos de controle e segregação que incidiram sobre a população negra em três períodos: 1) o século XIX, com o surgimento das teorias racialistas e eugenistas, que balizavam as políticas de branqueamento no Brasil; 2) as primeiras décadas do século XX, particularmente na cidade de São Paulo, onde crianças negras eram institucionalizadas em nome do 'mito da raça paulistana'; e 3) o início do século XXI, nos anos 2000, com a realização do Censo Psicossocial dos Moradores em Hospitais Psiquiátricos do Estado de São Paulo ${ }^{10}$ que, ao lado da leitura crítica de autores como Barros, Batista, Dellosi e Escuder sobre o Censo" ${ }^{11}$, trouxeram visibilidade à perspectiva racial. Na esteira da direção ético-política da Reforma Psiquiátrica Brasileira e em uma perspectiva decolonial, propomos o 'aquilombamento' da reforma como assunção ativa de um agir antirracista.

\section{Racismo científico e política de branqueamento no Brasil: propostas manicomiais eugênicas}

A discriminação e a opressão de negros(as) no Brasil não se iniciaram com as postulações do racismo científico. Contudo, partiremos desse ponto histórico, embora se saiba que, em outros períodos do Brasil colonial e imperial (sendo este compreendido de 1822 até o final do século XIX), o(a) negro(a) foi aviltado(a) de sua condição de sujeito, como aponta Souza ${ }^{12}$ :

A sociedade escravista, ao transformar o africano em escravo, definiu o negro como raça (noção ideológica), demarcou o seu lugar, a maneira de tratar e ser tratado, os padrões de interação com o branco, e instituiu o paralelismo entre cor negra e posição social inferior12(19).

A abolição da escravidão e a queda da monarquia, no final do século XIX, exigiram mudanças nas relações raciais no Brasil. Com o fim do escravismo, ao menos no papel, os negros(as) deixavam de ser peças, objetos. Todavia, surgia, paralelamente ao movimento abolicionista, novas correntes que negavam "a igualdade e a transformava em matéria de utopia"13(42). De 1870 em diante, produções teóricas começaram a ser elaboradas por diversos intelectuais, com o intuito de demonstrar uma suposta naturalização das disparidades sociais ${ }^{13,14}$ como falsa justificativa da manutenção de negros(as) em condição análoga à escravidão. A ideologia do branqueamento encontrou fertilidade na medicina eugenista do século XIX.

No Brasil, qualquer teoria que não balizasse diferenças naturais entre raças tinha pouco valor.

Aqui ocorreu uma releitura original. Ao mesmo tempo em que se absorveu a ideia de que as raças significavam realidades essenciais e ontológicas, negou-se a noção de que a mestiçagem levava sempre à degeneração ${ }^{\mathbf{1 4}(42)}$

As teorias apostavam que a miscigenação embranqueceria a nação brasileira e que tal embranquecimento traria uma evolução racial: "Miscigena-se para 'embranquecer' jamais para 'empretecer'. Com esses princípios, com essas crenças, convive a sociedade brasileira até hoje"15(3).

Aspecto importante nas relações raciais entre brancos e negros é o conceito de 'ideologia 
do branqueamento'. Incipiente na escravidão colonial, esse conceito teve seu fortalecimento cultural na edificação do abolicionismo brasileiro, tornando-se um dos eixos fundamentais do fim do regime de produção colonial, como ideário de um país miscigenado ${ }^{16}$.

O período de abolição da escravidão sofreu brutal interferência das políticas de incentivo à imigração europeia que pretendiam retirar os(as) negros(as) dos espaços de trabalho e de produção, substituindo-os(as) por imigrantes europeus. Na segunda metade do século XIX até os últimos anos do império, a busca de embranquecer o Brasil se fez política. Uma breve observação, aqui, faz-se necessária. Como uma tentativa de eliminação da raça negra, o branqueamento não se efetuou no Brasil, pois, atualmente, este é o país com o maior contingente de negros fora da África, perdendo somente para a Nigéria. Segundo a Pesquisa Nacional por Amostra de Domicílios (PNAD) - 2013, os(as) negros(as) representam $53,1 \%$ da população brasileira; em números absolutos, somam 107 milhões de habitantes ${ }^{17}$.

Na construção da noção de raça, as ciências biológicas tiveram importante papel, principalmente entre os anos 1870 e 1930, balizando as justificativas raciais de que o(a) negro(a) é inferior ${ }^{\mathbf{1 4}}$. "Tendo por base uma ciência positivista e determinista, pretendia-se explicar com objetividade - a partir da frenologia [...] - uma suposta diferença entre os grupos humanos"14, assim, por meio de análises fenotípicas, a biologia passou a patologizar determinados grupos humanos, por meio das teorias raciais da época.

Pesquisando a história da Liga Brasileira de Higiene Mental (LBHM), nas décadas de 1920 e 1930, no Brasil, Costa ${ }^{18}$ discute as bases eugenistas da psiquiatria então emergente:

Os eugenistas serviram-se do organismo para reforçar as ideias eugênicas e reativar o racismo puro, recalcado na cultura brasileira, com fina-

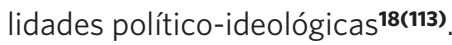

O mesmo autor aponta que, dando sequência às ideias de Nina Rodrigues, outros intelectuais surgiram nessa década, como Batista Lacerda e Roquette Pinto, que defendiam a superioridade de "caracteres mentais, somáticos, psicológicos e culturais da raça branca"18(66). De acordo com Bento19, Nina Rodrigues (1862 - 1906) já defendia a tese de que o(a) negro(a) foi escravizado(a) por causa de sua inferioridade.

Segundo Schwarcz' ${ }^{\mathbf{1 4}}$, em meados de 1930, a medicina no Brasil estava em plena construção, e sua hegemonia era fortemente disputada por duas grandes escolas: a Faculdade de Medicina do Rio de Janeiro e a Faculdade de Medicina da Bahia.

\begin{abstract}
O tema racial é ainda relevante, pois integra o arsenal teórico de ambas as escolas. Na Bahia, é a raça, ou melhor, o cruzamento racial que explica a criminalidade, a loucura, a degeneração. Já para os médicos cariocas, o simples convívio das diferentes raças que imigraram para o país, com suas diferentes constituições físicas, é que seria o maior responsável pelas doenças, a causa de seu surgimento e o obstáculo à 'perfectibilidade' biológica14(191).
\end{abstract}

Costa $^{18}$ aponta que os médicos Renato Kehl e Xavier de Oliveira protagonizavam as teorias racistas dentro da LBHM. $\mathrm{O}$ autor observa também que os demais psiquiatras condescendiam com suas asseverações racistas, afinal, ambos nunca foram questionados pelos demais integrantes da Liga; pelo contrário, suas proposições eram aceitas. São exemplos o III Congresso de Psiquiatria e o III Congresso Brasileiro de Neurologia, Psiquiatria e Medicina Legal, em que Xavier de Oliveira ${ }^{18}$ proferiu:

nำ: que só seja permitida a entrada no paiz de immigrantes da raça branca; no7: que seja expressamente prohibido para effeito de residência além de seis meses, a entrada, no paiz, de quaesquer elementos das raças negra e amarella18(111).

Renato Kehl'18, por sua vez, declarava a respeito da mestiçagem: 
Os dois elementos cruzados têm, cada um, seus caracteres psicofísicos estritamente próprios, estáveis, harmoniosos. Em vez de realizar uma média entre esses caracteres diferentes, a mestiçagem perturba seu desenvolvimento natural. Aqueles que afirmam, tanto entre brancos e negros, como entre brancos e índios, mongóis e outros. Os mestiços não podem ser comparados a uma raça pura; só a partir de uma visão falsa é que se pode admitir sua igualdade e superioridade ${ }^{\mathbf{1 8 ( 1 1 1 )}}$.

Costa $^{18}$ considera que as interpretações das estatísticas psiquiátricas tinham fortes componentes racistas. As estatísticas eram o fundamento médico, todavia, esses dados não levaram em consideração determinantes sociais e históricos. O racismo admitido pela LBHM, nos anos 1930, pautava-se nos altos índices de doença mental e sua prevalência nos grupos 'étnicos não brancos' (linguagem da época). Também se ancorava no tipo de doença mental toxinfecciosa (como sífilis e alcoolismo), uma vez que o grupo populacional branco apresentava predominantemente doenças nomeadas constitucionais.

Segundo o autor, esses dados eram utilizados e interpretados como estigma racial, visto que

os psiquiatras tinham nas estatísticas um pretexto para confirmar o preconceito racial. Os indivíduos não brancos, sendo portadores hereditários de predisposição sifilítica, representavam um perigo para a constituição eugênica do Brasi|18(112).

Ancorados nessas estatísticas, doenças relacionadas com uma suposta predisposição genética das mulheres negras em contrair sífilis e com uma decadência moral/sexual eram atribuídas à herança psíquica de negros e mestiços. Essas são análises extremamente preconceituosas e racistas que ignoravam as condições sociais desumanas que homens negros e mulheres negras viveram ao longo dos anos, violências determinantes para a manifestação desses fenômenos.
Para Serra e Scarcelli20, a ciência médica eugênica tinha, como principal intenção, a patologização de negros(as), indígenas e descendentes de asiáticos(as), além de afirmar uma suposta periculosidade das classes pobres e ratificar o ideário da branquitude.

No final dos anos 1930, a política de branqueamento, aos poucos, perdeu força, assim como o alienismo entra em declínio. Contudo, sua tarefa manicomial eugênica já havia produzido efeitos, assim como função simbólica, material e política, conforme aponta o próximo item.

\section{População negra e manicomialização}

Este item fará referência à manicomialização da população negra em três períodos distintos. O primeiro deles é o racismo científico das últimas décadas do século passado, mais especificamente, a obra de Dr. Henrique Roxo, que aproximou raça e loucura, tratando a comunidade negra da época como intelectualmente inferior e/ou degenerada ${ }^{21}$.

Sempre ciosos de resguardar a vastidão e a imprecisão dos limites definidores da doença mental, os psiquiatras partiram do princípio de que a loucura não escolhia raça, o que não os impediu de construir, sub-repticiamente, relações bastante próximas entre doença mental

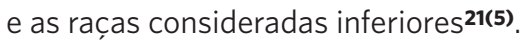

Engel21, ao analisar a obra do Dr. Henrique Roxo (1904), verificou que o médico se ancorava na comunidade científica do Rio de Janeiro para postular suas associações entre raça negra, inferioridade intelectual, loucura e degeneração. Tal associação "poderia ser utilizada como um instrumento importante para justificar e legitimar a implantação de mecanismos mais sutis de controle social"21(5).

O Dr. Henrique Roxo analisou o 'Quadro estatístico dos doentes internados no pavilhão de observação do Hospital Nacional de Alienados - HNA (1894-1903)', reproduzido no quadro 1. 
Quadro 1. Quadro estatístico dos doentes internados no pavilhão de observação do Hospital Nacional de Alienados (1894-1903)

\begin{tabular}{lllll}
\hline Ano & População total & Brancos & Pardos & Pretos \\
\hline 1894 & 418 & 217 & 91 & 110 \\
1895 & 606 & 349 & 130 & 127 \\
1896 & 623 & 389 & 128 & 106 \\
1897 & 704 & 381 & 151 & 172 \\
1898 & 707 & 396 & 179 & 152 \\
1899 & 697 & 379 & 168 & 150 \\
1900 & 615 & 356 & 132 & 127 \\
1901 & 608 & 333 & 153 & 122 \\
1902 & 614 & 328 & 159 & 127 \\
1903 & 657 & 321 & 203 & 133 \\
\hline
\end{tabular}

Fonte: Enge|21(6)

Para sua surpresa, com exceção de 1903, o número de pretos e pardos somados é inferior ao número de brancos, o que levou o médico a fazer observações/interpretações de que:

a taxa de negros internados era considerável e, neste sentido, argumenta que os brancos incluíam os estrangeiros e que os pretos eram quantitativamente inferiores aos brancos na cidade do Rio de Janeiro ${ }^{21(6)}$.

O médico constatava uma presença percentual maior de pretos e pardos internados, em comparação aos brancos, quando comparava com na população da cidade do Rio de Janeiro, embora não tenha feito um levantamento quantitativo rigoroso, comprovando uma falaciosa ideia de inferioridade e periculosidade.

Analisando o quadro [...] ele afirma, por exemplo, que a mania é mais rara nos negros do que a lypemania (melancolia delirante), argumentando ser a primeira 'uma manifestação dos cérebros de evolução normal' e, portanto, mais rara nos 'tipos da raça inferior', enquanto em relação à segunda 'temos observado ser própria dos cérebros menos inteligentes'. Afirma ainda que a imbecilidade não seria muito frequente nos pacientes negros, mas apressa-se a esclarecer estar se referindo às manifestações mórbidas, uma vez que: 'As raias da imbecilidade atingem, em geral, todos os pretos'21(6).

Com esses e outros argumentos, o psiquiatra conclui sua tese justificando não apenas as internações da população negra em manicômios, mas a suposta inferioridade dessa população, o que abonaria determinados tipos de relações sociais e de trabalho hierarquizadas racialmente, tornando-se um modo de controle social.

Nas primeiras décadas do século XX, ainda na região Sudeste, porém, na cidade de São Paulo, outro famoso médico psiquiatra praticava a manicomialização com princípios eugenistas, dessa vez, com crianças, sendo possível identificar que

o Juquery, nesse momento, servia de palco de uma psiquiatria experimental que buscava solucionar as dificuldades enfrentadas pelo crescimento da cidade de São Paulo20(86).

Em nome e em busca do 'mito da raça paulistana', aperfeiçoado por uma ideologia de heróis bandeirantes, políticas eugenistas foram implementadas, buscando a normalização, a disciplina e o branqueamento. O médico psiquiatra Pacheco e Silva foi um dos grandes protagonistas desse processo, como mostram as autoras Serra e Scarcelli20: 
$\mathrm{O}$ argumento central em favor do tratamento de internação para os "menores anormais" era que a prevenção e as medidas educativas corretivas diminuiriam os gastos do Estado com a construção de novos presídios. E Pacheco e Silva tinha convicção dessa proposta, já que estimava que metade dos presidiários apresentavam anomalias neuropsíquicas que poderiam ter sido evitadas pela assistência precoce e o tratamento adequado ${ }^{\mathbf{2 0}(\mathbf{9 3}) .}$

Desse modo, o psiquiatra justificava a internação de crianças e indicava que isso deveria acontecer o mais cedo possível, assim, os riscos seriam menores para a sociedade. A internação das crianças em hospitais psiquiátricos, segundo o médico, permitiria a investigação da 'personalidade delinquente'. Tratava-se de uma pesquisa que utilizaria a metodologia de 'decomposição sintética da personalidade', que comportaria a análise de fatores biográficos, genealógicos e sociológicos, que iriam compor essa 'personalidade', 'deformando' o indivíduo com o passar dos anos 20 .

Pacheco e Silva, embora fosse jovem, era um influente médico, com importante entrada no cenário político da época. Suas apostas clínicas recebiam financiamento, o que permitiu a construção da Escola Pacheco e Silva, dentro do Hospital do Juquery, em 1929, para estudar os 'menores anormais' e 'abandonados', buscando a prevenção e a cura da delinquência20.

Mais uma vez, a psiquiatria foi aplicada em busca de padrões normativos, propondo a 'delinquência' como

consequência das patologias específicas de cada menor, e o crime seria compreendido pelas disfunções 'anormais' do corpo, fosse por herança biológica, fosse pelas condições de vida, e não como reflexo de estruturas econômicas, sociais e políticas 20(93).

Percebemos que o aumento do contingente populacional nas cidades paulistas pressupunha, aos psiquiatras da LPHM [Liga Paulista de Higiene Mental], novas formas de 'ordenar' e 'controlar' a vida. Nesse sentido, amparados pelo caráter científico da higiene mental e da eugenia, ações profiláticas, preventivas e restritivas foram utilizadas de diversas formas com o intuito de 'aperfeiçoar' a genética populacional. Vimos como a ideia de uma raça 'pura', tão utilizada em países europeus, precisou ser revista e adaptada às condições brasileiras. Se somos um país de miscigenados, essa característica não poderia fadar o fracasso brasileiro. Para evitar o descontentamento dos ideais de uma raça superior, a mistura racial foi bem aceita e encarada com certo otimismo. Para os psiquiatras da LPHM, se houvesse a miscigenação, em algumas décadas, haveria o embranquecimento populaciona|20(94).

É necessário frisar que esse processo eugenista com foco na infância ocorreu em razão da incumbência de médicos psiquiatras cumprirem um projeto de excelência racial para o Estado $^{20}$, no qual negros(as) não iriam fazer parte do 'mito da raça paulistana'.

Outro período a ser abordado é o das décadas de 1960 a 1980, marcado pela vigência do regime de ditadura militar no Brasil. As informações referentes ao quantitativo de negros(as) em manicômios nesses anos são praticamente inexistentes ou pouco confiáveis. Por exemplo, no censo de 1970, a pergunta sobre raça/cor foi suprimida, sendo que o Instituto Brasileiro de Geografia e Estatística (IBGE) foi impedido de coletar dados que levassem em consideração raça/cor como marcador social da diferença ${ }^{22}$.

A herança manicomial racista dos anos antecedentes somada às difíceis condições vigentes no Brasil, impostas pela ditadura militar desde 1964, fizeram com que a população negra compusesse maioria nos hospitais psiquiátricos. Sem os dados estatísticos da época, optamos por não desenvolver análises sobre esse período, todavia, sugerimos que os registros fotográficos do período podem sustentar a afirmação de que a manicomialização teve/ tem cor no Brasil do regime militar. Daniela Arbex ${ }^{23}$, em seu livro 'Holocausto brasileiro', 
publicado em 2013, apresenta uma gama de imagens que permite essa compreensão.

Brum $^{24}$, ao prefaciar o livro de Arbex, aponta que, entre os internos, "cerca de 70\% não tinham diagnóstico de doença mental. Eram epiléticos, alcoolistas, homossexuais, prostitutas, gente que se rebelava, gente que se tornara incômoda para alguém com mais poder", lógica manicomial que não foi (totalmente) abandonada com a virada do século, conforme veremos nos próximos parágrafos.

Por fim, chega-se aos anos 2000, mais especificamente, a partir de 30 de novembro de 2007, data adotada como linha-base para Censo Psicossocial dos Moradores em Hospitais Psiquiátricos do Estado de São Paulo ${ }^{10}$.

O censo citado "identificou que 6.349 pessoas moram em 56 dos 58 hospitais psiquiátricos existentes no estado"10. Quando os autores analisaram os números,

constataram que, enquanto $27,4 \%$ da população do estado de São Paulo se autodeclara preta e parda, entre os moradores dos hospitais psiquiátricos do estado de São Paulo, esse percentual é de 38,36\%11(1.237).

Barros et al.11 consideram que os números apontados pelo censo permitem constatar uma presença maior de moradores(as) negros(as) em hospitais psiquiátricos do que quando comparado com a população geral no estado de São Paulo. Os autores sugerem que é importante pensar sobre o

impacto dos processos ininterruptos de preconceito, exclusão, abandono e apartamento social na saúde mental; so bre populações vulneráveis e saúde mental e/ou sobre os 'efeitos psicossociais do racismo'11(1239).

A pesquisa não se limitou ao número de moradores nos hospitais psiquiátricos; dessa forma, foram também analisados aspectos como a situação conjugal dos moradores internados e os dados de escolaridade. Em ambos os aspectos, a condição da população negra chama a atenção: o estado civil informado é predominantemente solteiro tanto para homens (média de $84,7 \%$ para pretos e pardos) quanto para mulheres (média de $74 \%$ para pretas e pardas) [...] na população total do censo, o percentual é de $82,1 \%{ }^{11(1240)}$.

A lógica da organização das instituições totais é arquitetada para que não ocorram encontros, os pátios são separados, os horários de banho e sol são separados, a vida segue o ritmo institucional, os desejos ficam submetidos à censura dos vigias. Essa lógica, sustentada nos princípios eugênicos e profiláticos do final do século XIX e princípio do século XX no Brasil, silencia a expressão das formas particulares de existêncian1(1240).

Segundo os autores, os dados sobre escolaridade são espantosos, chegando a somar $70 \%$ de "analfabetos"11; destes, $9 \%$ sabem apenas escrever o próprio nome.

Essa realidade mostra-se mais perversa em relação aos pretos e pardos, pois esse extrato da população moradora totaliza $64,8 \%$ de analfabetos entre os seus 2.435 não cidadãos ${ }^{11(1241)}$.

A barreira do analfabetismo aprofunda os mecanismos de exclusão social dessa população porque a impede de exercer o ato mínimo de sobrevivência, que é ler e compreender o mundo. Por meio da leitura e da escrita, é possível ampliar repertórios pessoais, ajuizar valores e eventos, participar da vida política e civil, organizar-se como cidadão de direitos.

A escolaridade de mulheres e homens brancos distribui-se entre os diferentes níveis de escolaridade. Dentre os pretos e pardos, prevalecem os não alfabetizados. $\mathrm{O}$ analfabetismo expressa mais um dos direitos negados a essas pessoas, e aprofunda os mecanismos de exclusão social, dificultando sua participação na vida política e civi|11(1241).

Quando são investigados os motivos de permanência nos hospitais psiquiátricos, o 
estudo demonstra a 'precariedade social', aqui entendida como a inexistência de uma morada fora do hospital e/ou a impossibilidade de renda. Considera-se que cerca de $65,3 \%$ das pessoas estão internadas em hospitais psiquiátricos por causa da precariedade social somada ao transtorno mental ou às doenças clínicas, sendo que $8,2 \%$ das pessoas (totalizando 519) estão internadas exclusivamente pela precariedade social.

Essa realidade, quando analisada com o recorte raça/cor, deflagra diferentes contextos para brancos(as) e negros(as):

$11,4 \%$ dos moradores pretos, 9,3\% dos brancos e $8,0 \%$ dos homens pardos. Dentre as mulheres esse percentual é de 8,2\% entre as pretas, 6,3\% entre as brancas e 4,7\% entre as moradoras

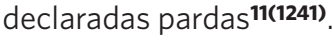

Ao compreendermos população negra como a somatória de pretos(as) e pardos(as), os dados apontam que, dos internados por 'precariedade social', 19,4\% são homens negros, enquanto 9,3\% são homens brancos; e, entre as mulheres, o dado não é diferente, pois $12,9 \%$ são mulheres negras, enquanto $6,3 \%$ são mulheres brancas. Em ambos os gêneros, o número de negros e negras internados por 'precariedade social' é mais do que o dobro quando comparado aos brancos e brancas.

A população negra sofre historicamente processos ininterruptos de abandono e apartamento social. O lugar por excelência do abandono e exclusão social é o manicômio, assim como outras instituições totais. Os dados consolidados comprovaram que à população negra cabe a injusta posição de prioritária no ranking da exclusão social nos hospitais psiquiátricos do estado de São Paulon11(1240).

Finalizamos este item com a compreensão de que a relação entre loucura e população negra exige que escutemos as vozes daqueles(as) que foram e estão sendo manicomializados, ou seja, os(as) negros(as). Para estes(as), a escansão racial existente nos manicômios nunca passou despercebida, 'em branco', como não passou para Lima Barreto ${ }^{25}$, nos seus relatos (autobiográficos), assim como nos livros Diário do hospício e O cemitério dos vivos, pois evidenciam a realidade racial dos hospitais psiquiátricos. Nas palavras dele:

Esse pátio é a coisa mais horrível que se pode imaginar. Devido à pigmentação negra de uma grande parte dos doentes aí recolhidos, a imagem que se fica dele é que tudo é negro. $\mathrm{O}$ negro é a cor mais cortante, mais impressionante; e, contemplando uma porção de corpos negros nus, faz ela que as outras se ofusquem no nosso pensamento. É uma luz negra sobre as coisas, na posição de que, sob essa luz, o nosso olhar pudesse ver alguma coisa $\mathbf{2 5 ( 2 1 1 )}$

\section{Aquilombar a Reforma Psiquiátrica Brasileira: uma exigência antimanicomial}

A vinculação entre população negra e loucura é secular no Brasil. Porém, reconhecer os efeitos desse atrelamento, em seus distintos contextos sociais e políticos ao longo dos anos, oferece-nos elementos para produzir um ethos compromissado com o aquilombamento e com a necessária desconstrução do crioulo doido ${ }^{26} \mathrm{e}$ da negra maluca. Essa manicomialização teve, no decorrer do tempo, diferentes formas que vão do abono das crises socioeconômicas das primeiras décadas do regime republicano, em razão da abolição da escravatura, à famigerada busca antiabolicionista; à 'arianização'; ao combate de vícios como o álcool e o tabaco; ao incentivo de 'bons hábitos, atividade física e intelectual'; à política do branqueamento e às práticas de controle de imigração dos considerados 'inaptos'; à proibição de casamento entre os ditos 'anormais'; à esterilização dos 'degenerados', atualizando-se no genocídio da população pobre, preta e periférica; assim 
como à guerra contra as drogas e ao combate em relação ao crack ${ }^{11,14,20,26-28}$. Independentemente de sua forma e ação, o escopo central dessas práticas, ao longo dos anos, tem sido o controle social a partir da interseccionalidade raça/cor, classe social e gênero. Assim, consideramos que, no Brasil, não haverá Reforma Psiquiátrica plena enquanto a Luta Antimanicomial não compuser a luta antirracista interseccionada a essas outras lutas.

Se o racismo é estrutural, "decorrência da própria estrutura social, ou seja, do modo 'normal' com que se constituem as relações políticas, econômicas, jurídicas e até familiares, não sendo uma patologia social"29(38), e, muitas vezes, institucionalizado, na medida em que expressa o "fracasso das instituições e organizações em prover um serviço profissional e adequado às pessoas devido à sua cor, cultura e origem racial ou étnica"30(2); trata-se de traçar estratégias e propostas para que a dimensão racial ganhe centralidade no debate da saúde mental brasileira.

Estudo recente ${ }^{31}$ aponta que: "problematizar o manicômio e suas expressões, abordando as relações de raça, gênero e classe, é ultrapassar os próprios muros que compõem a formação social brasileira"31(14), para isso, "racializar os corpos e a própria história faz parte dos novos rumos da Luta Antimanicomial”31(14). Nessa esteira, anuímos à provocação de Santos:

levando em conta estarmos num mundo feito para os brancos, sob o signo do genocídio e o sentimento de 'inexistência', nossa decisão da produção da saúde mental do negro está só começando32(257)

Assim, surgem, recentemente, importantes trabalhos como os de Passos ${ }^{31}$; Oliveira, Duarte e Pitta ${ }^{33}$ e David, Silva, Silva e Lucas ${ }^{34}$.

De fato, se já temos, hoje, no campo das políticas de saúde, especialmente nos marcos legais (ou na dimensão jurídico-política), disposições para não "ignorar as relações raciais e o gravíssimo problema de saúde mental da maioria da população brasileira, que é o preconceito racial"32(244), é fundamental ampliarmos os estudos e as ações de cuidado que abordem o preconceito racial e seu impacto na saúde mental da população brasileira ${ }^{32}$. Nessa direção, Santos ${ }^{32}$ afirma que o Estado não determina apenas quem deve morrer $\mathrm{e}$ quem deve viver, mas também "os que devem ter saúde mental, e os que podem viver atormentados em seu sofrimento produzido pelas condições sociais"29(247), e acrescenta que

é o Estado racista também que determina sob quais condições tratamos da saúde mental da população brasileira, que tipo de investimento, com quais psicologias e quais abordagens ${ }^{29(247)}$.

Atentar-se aos saberes utilizados pela Reforma Psiquiátrica Brasileira ao longo dos anos de Luta Antimanicomial é olhar para o que subsidia e autoriza o fazer das equipes de saúde mental, em especial, na esfera da saúde pública $^{35}$. Adotar uma perspectiva decolonial na Reforma Psiquiátrica Brasileira irá ampliar e fortalecer o saber/fazer de saúde, utilizados no campo psicossocial da saúde mental, como sugere a campanha 'O SUS está de braços abertos para a saúde da população negra'36, que objetiva a

inclusão de práticas culturais afro-brasileiras, [...] entre outras manifestações ancestrais e contemporâneas de artes negras, nos programas de promoção da saúde ${ }^{36(27)}$.

Abdias Nascimento ${ }^{37}$ aponta o quilombismo como uma práxis de libertação da opressão e assunção da própria história pelo povo afro-brasileiro que se inspira no quilombo como um modelo de organização dinâmica, em exercício desde o século XV, enquanto formulação política de garantia de humanidade e comunidade em suas dimensões subjetivas e sócio-histórica.

Inspirados no autor, chamamos de aquilobamento uma direção ético-política antirracista que exige um alargamento de todas as bases vigentes na reforma psiquiátrica, 
especialmente quanto às relações entre saúde mental e racismo, e um agir em saúde que contribua para a promoção da equidade racial e para a desinstitucionalização do racismo. Essa atitude ético-política exige análise crítica permanente dos efeitos do racismo nos processos de trabalho nos serviços de saúde/ saúde mental e um radical projeto de atenção aos efeitos do racismo como uma questão antimanicomial.

Nesse projeto, é necessário escapar da cilada eurocêntrica que baliza (de modo patriarcal) nossa Reforma Psiquiátrica, tomando como principais (ou únicos) referenciais os modelos italianos e franceses de desinstitucionalização, e incorporar as experiências e saberes afro-ameríndios, a exemplo do que ocorre na Rede Nacional de Religiões Afro-Brasileiras e Saúde (Renafro), que compõe o SUS em uma perspectiva de saber-fazer afrodiaspórica. Trata-se de (re)tomar criticamente as epistemologias e práticas utilizadas pela Reforma Psiquiátrica Brasileira, abrindo espaço para outros modos de saber, pensar e cuidar, considerando a singularidade de cada usuário/sujeito atendido em seus distintos territórios, respeitando os direitos humanos, garantindo direitos sociais, atendendo ao princípio de equidade racial tanto nas condições de vida da população quanto no impacto no perfil de saúde, e, acima de tudo, levando em conta o papel do racismo na história do País, que ganha maior evidência no atual momento político-social.

Esse é um projeto mais urgente no atual momento na medida em que "nos últimos tempos, temos assistido ao avanço de forças conservadoras - força política ancorada no fundamentalismo conservador e ultraliberal na economia"38(3-4), exigindo a organização de gestores(as), trabalhadores(as) e sociedade civil na luta pela sustentação e ampliação de recursos para as políticas públicas sociais e na garantia dos direitos sociais, atentando para iniquidades raciais.

\section{Colaboradores}

David EC (0000-0002-2571-3133)* contribuiu para a revisão de literatura e para a elaboração do manuscrito. Vicentin MCG (0000-00031718-6721)* contribuiu para a elaboração do manuscrito. 


\section{Referências}

1. Bauru. Manifesto de Bauru. In: II Congresso Nacional de Trabalhadores em Saúde Mental: por uma sociedade sem manicômios. [internet]. Bauru; 1987. [acesso em 2020 fev 17]. Disponível em: https://site. cfp.org.br/wp-content/uploads/2017/05/manifesto-de-bauru.pdf.

2. Bauru. Carta de Bauru - 30 anos. In: Encontro de Bauru: 30 anos por uma sociedade sem manicômios. [internet] Bauru, SP. 8-9 dez 2017. [acesso em 2019 dez 10]. Disponível em: http://site.cfp.org.br/wp-content/ uploads/2017/12/CARTA-DE-BAURU-30-ANOS.pdf.

3. Amarante P, coordenador. Loucos pela vida: A trajetória da reforma psiquiátrica no Brasil. Rio de Janeiro: Fiocruz; 1998.

4. Yasui S. Rupturas e encontros: desafios da Reforma Psiquiátrica Brasileira. Rio de Janeiro: Fiocruz; 2014.

5. Quijano A. Colonialidade do poder e classificação social. In: Santos BS, Meneses MP, organizadores. Epistemologias do Sul. São Paulo: Cortez; 2000.

6. Brasil. Ministério da Saúde. Portaria $n^{\circ} 3.088$, de 23 de dezembro de 2011. Institui a Rede de Atenção Psicossocial para pessoas com sofrimento ou transtorno mental e com necessidades decorrentes do uso de crack, álcool e outras drogas, no âmbito do Sistema Único de Saúde. Diário Oficial da União. 26 Dez 2011. [acesso em 2020 set 20]. Disponível em: http://bvsms.saude.gov.br/bvs/saudelegis/gm/201l/ prt3088_23_12_2011_rep.html.

7. Brasil. Ministério da Saúde, Secretaria Executiva. Legislação em saúde mental: 1990-2002.3. ed. Brasília, DF: Ministério da Saúde; 2002.

8. Brasil. Ministério da Saúde, Secretaria de Gestão Estratégica e Participativa. Departamento de Apoio à Gestão Participativa. Política Nacional de Saúde Integral da População Negra - Uma política do SUS. Brasília, DF: Ministério da Saúde; 2010.

9. David EC. Saúde mental e racismo: a atuação de um
Centro de Atenção Psicossocial II Infantojuvenil [dissertação] [internet]. São Paulo: Pontifícia Universidade Católica de São Paulo Programa de Estudos Pós-Graduados em Psicologia Social, PUC; 2018. 168 p. [acesso em 2019 nov 1]. Disponível em: https://tede2. pucsp.br/handle/handle/21029.

10. Barros S, Bichaff R, organizadores. Desafios para a desinstitucionalização: censo psicossocial dos moradores em hospitais psiquiátricos do Estado de São Paulo. [internet]. São Paulo: Secretaria de Estado da Saúde; 2008. [acesso em 2015 nov 1]. Disponível em: http://pfdc.pgr.mpf.mp.br/atuacao-e-conteudos-de-apoio/publicacoes/saude-mental/censo_psicossocialsP.pdf.

11. Barros S, Batista LE, Dellosi ME, et al. Censo psicossocial dos moradores em hospitais psiquiátricos do estado de São Paulo: um olhar sob a perspectiva racial. Saúde Soc. 2014 [acesso em 2020 out 14]; 23(4):1235-1247. Disponível em: https:// www.scielo.br/scielo.php?script=sci_arttext\&pid =S0104-12902014000401235.

12. Souza NS. Tornar-se negro, ou, as vicissitudes da identidade do negro brasileiro em ascensão social. Rio de Janeiro: Graal; 1983.

13. Schwarcz LM. Racismo no Brasil. São Paulo: Publifolha; 2001.

14. Schwarcz LM. O espetáculo das raças: cientistas, instituições e questão racial no Brasil - 1870-1930. São Paulo: Companhia das Letras; 1993.

15. Deus ZA. A questão racial no Brasil. [internet] Laboratório de Políticas Públicas/UERJ - Observatório Latino-Americano de Políticas Educacionais. Programa Políticas da Cor na Educação Brasileira; 2000. [acesso em 2018 maio 27]. Disponível em: http://www. lppuerj.net/olped/documentos/ppcor/0090.pdf.

16. Carone I, Bento MAS, organizadores. Psicologia social do racismo: estudos sobre a branquitude e branqueamento no Brasil. Rio de Janeiro: Vozes; 2002.
${ }^{*}$ Orcid (Open Researcher and Contributor ID). 
17. Instituto Brasileiro de Geografia e Estatística. Pesquisa nacional por amostra de domicílios: síntese de indicadores. [internet] 2. ed. Rio de Janeiro: IBGE; 2015. [acesso em 2019 jan 27]. Disponível em: https://biblioteca.ibge.gov.br/visualizacao/livros/ liv94414.pdf.

18. Costa JF. História da psiquiatria no Brasil: um corte ideológico. 5. ed. rev. Rio de Janeiro: Garamond; 2006.

19. Bento MAS. Branqueamento e branquitude no Brasil. In: Carone I, Bento MAS, organizadores. Psicologia social do racismo: estudos sobre a branquitude e branqueamento no Brasil. Rio de Janeiro: Vozes; 2002.

20. Serra LN, Scarcelli IR. Por um sangue bandeirante: Pacheco e Silva, um entusiasta da teoria eugenista em São Paulo. Rev. latinoam. psicopatol. fundam. [internet]. 2014 [acesso em 2019 fev 26]; 17(1):85-99. Disponível em: http://www.scielo.br/pdf/rlpf/vl7nl/ v17nla07.pdf.

21. Engel MG. As fronteiras da 'anormalidade': psiquiatria e controle social. Hist. cienc. Saúde-Manguinho [internet]. 1999 [acesso em 2019 jan 17]; 5(3):547-63. Disponível em: http://www.scielo.br/scielo.php?script=sci arttext\&pid=S0104-59701999000100001.

22. Memórias da Ditadura. CNV e negros. [internet] [São Paulo]. [acesso em 2020 set 20]. Disponível em: http:// memoriasdaditadura.org.br/cnv-e-negros/.

23. Arbex D. Holocausto brasileiro. São Paulo: Geração Editorial; 2013.

24. Brum E. Os loucos somos nós. (Prefácio). In: Arbex D. Holocausto brasileiro. São Paulo: Geração Editorial; 2013. p. 13-17.

25. Barreto L. O cemitério dos vivos. São Paulo: Cosac Naify; 2010.

26. Nascimento EL. O sortilégio da cor: identidade raça e gênero no Brasil. São Paulo: Summus; 2003.
27. Hart C. Um preço muito alto: a jornada de um neurocientista que desafia nossa visão sobre as drogas. Rio de Janeiro: Zahar; 2014.

28. Small D. A guerra às drogas facilita a criminalização de pobres e negros. [internet]. 2016. [acesso em 2017 fev 21]. Disponível em: https://www.geledes.org.br/ deborah-small-guerra-as-drogas-facilita-criminalizacao-de-pobres-e-negros/.

29. Almeida SL. O que é racismo estrutural? Belo Horizonte: Letramento; 2018.

30. Department for International Development DFID. Combate ao racismo institucional. Brasília, DF: CRI; 2007.

31. Passos RG. "Holocausto ou Navio Negreiro?": inquietações para a Reforma Psiquiátrica brasileira. Argum. [internet], 2018 [acesso em 2020 jul 22]; 10(3):10-22. Disponível em: http://periodicos.ufes.br/argumentum/article/view/21483.

32. Santos AO. Saúde Mental da população negra: Uma perspectiva não institucional. Revista da ABPN [internet]. 2018 [acesso em 2019 jul 18]; 10(24):241-259. Disponível em: http://www.abpnrevista.org.br/revista/index.php/revistaabpnl/article/.

33. Oliveira IM, Duarte MJO, Pitta AMF. Racismo, sofrimento e saúde mental: um debate necessário. In: Oliveira W, Pitta A, Amarante P, organizadores. Direitos humanos \& saúde mental. São Paulo: Hucitec; 2017.

34. David ECD, Silva JA, Silva VP, et al. Racismo, branquitude e prática antirracista: questões iniciais para a atenção psicossocial. In: Núcleo de Relações Raciais: percursos, histórias e movimentos [internet]. Porto Alegre: Conselho Regional de Psicologia do Rio Grande do Sul; 2019. [acesso em 2020 jul 22]. Disponível em: https://www.crprs.org.br/conteudo/publicacoes/ebook_NRR_final.pdf.

35. Amarante P. Reforma Psiquiátrica e Epistemologia. Cad. Bras. Saúde Mental [internet] jan.-abr. 2009 [acesso em 2019 jul 12]; 1(1). Disponível em: http:// 
stat.necat.incubadora.ufsc.br/index.php/cbsm/article/viewFile/998/1107.

36. Brasil. Ministério da Saúde, Secretaria de Gestão Estratégica e Participativa, Departamento de Apoio à Gestão Participativa e ao Controle Social. O SUS está de braços abertos para a saúde da população negra (Material da campanha). Brasília, DF: Ministério da Saúde; 2017.

37. Nascimento A. O quilombismo: documentos de uma militância pan-africanista. 3. ed. rev. São Paulo: Perspectiva; Rio de Janeiro: Ipeafro; 2017.
38. Batista LE, Barros S. Enfrentando o racismo nos serviços de saúde. Cadernos de Saúde Pública [internet] 2017 [acesso em 2019 ago 22]; 33(supl1). Disponível em: http://www.scielosp.org/pdf/csp/v33s1/16784464-csp-33-sl-e00090516.pdf.

Recebido em 02/03/2020

Aprovado em 10/08/2020

Conflito de interesses: inexistente

Suporte financeiro: a pesquisa de mestrado base deste artigo foi

financiada com bolsa do Conselho Nacional de Desenvolvimento

Científico e Tecnológico (CNPq) 